\title{
Injury Rate in Professional Soccer Players within the Community of Madrid: A Comparative, Epidemiological Cohort Study among the First, Second and Second B Divisions
}

\author{
García-Fernández $\mathbf{P}^{1}$, Guodemar-Pérez $\mathrm{J}^{2}$, Ruiz-López $\mathbf{M}^{3}$, Rodríguez-López ES ${ }^{2}$ and Hervás-Pérez JP2* \\ ${ }^{1}$ Department of Physiotherapy, Health Sciences Faculty, University Alfonso X el Sabio, Madrid, Spain \\ 2Department of Physiotherapy, Health Faculty, Camilo José Cela University, Madrid, Spain \\ ${ }^{3}$ Departament of Nursing, Health Faculty, Camilo José Cela University, Madrid, Spain
}

\begin{abstract}
Background: Soccer is a sport with international reach and presence. Injury rates in this sport are high, and these have a high economic impact on soccer clubs.
\end{abstract}

Objectives: To report the incidence, type and circumstances of injuries sustained by professional soccer players in Spain across three playing categories: first division, second division, second division B.

Study design: A prospective, descriptive, epidemiological cohort study.

Participants: The inclusion criteria consisted of all male players with an existing contract within the first team. Players with old injuries were not excluded and neither were those who were injured when data collection began The number of players in the sample included 100 professional soccer players.

Methods: This prospective, observational study examined time-lost injuries occurring during 2016/2017 season among 100 male players from 4 soccer clubs based on a comprehensive data recording form.

Main Outcome Measurements: Date and mechanisms of injury, body area injured, diagnosis, severity, and time-off (days) for each player were collected.

Results: 142 injuries were recorded. The injury incidence rate was 2.58 injuries per 1000 hours exposure. The number of injuries decreased the higher the professional category, thus a statistically significant difference was found with a greater number on injuries in the second division B players (3.03) compared to first division (2.27) and second division (1.92). Direct player-to-player contact was responsible for $66.9 \%$ of injuries. The majority ( $80.98 \%)$ of injuries occurred in the lower limb, of which the thigh was the most injured area $(40 \%)$ followed by the knee $(19.13 \%)$. Muscle injuries were the most frequent form of injury $(52.10 \%)$, of which the hamstrings were the most affected muscle.

Conclusion: These findings help identify the most common injury patterns. This data may be used to improve current injury prevention programs.

Keywords: Epidemiology; Soccer; Lower extremity; Muscles

\section{Introduction}

In Spain, soccer is by far the sport with the most followers. There are 869,320 federated soccer players in Spain, and the number of clubs equals 21,027 [1]. In addition, the economic impact of soccer is vast, adding up to approximately $1 \%$ of the gross domestic product in Spain [2]. Furthermore, it is also one of the sports with the highest risk of injury. Indeed, several studies have confirmed that this sport is responsible for between 6 to 9 sports injuries per 1,000 hours exposure, which, compared to other sports, is a high figure [3-5]. In Europe, soccer is responsible for between 25 and 50 percent of sports injuries registered [6]. Only a few sports, such as rugby present incidence rates that are higher than soccer $[7,8]$. It is important to note that in professional soccer, any injury sustained by a player inevitably is associated with, on the one hand, suffering for the player, but also an important economic loss for the club, with the ensuing repercussion in first level events to follow [9]. Despite the high injury rates, there is no consensus regarding the number or injuries or the underlying mechanisms $[10,11]$. In order to help to inform an improved consensus regarding injury rate and bearing in mind the fact that soccer is the most practiced sport in Spain, this research project aimed to study professional soccer players in the community of Madrid in order to collect and describe the data regarding the number of injuries, the most frequent injuries, their distribution, type, location (tissues and anatomical location), moment in which these occurred, cause and severity. Furthermore, we sought to compare the injury rate among players from the different professional categories (first division, second division, second division B).

\section{Methods}

An epidemiological, observational, prospective and descriptive study was performed. The sample considered all the soccer teams of the $1^{\text {st }}, 2^{\text {nd }}$ and $2^{\text {nd }} \mathrm{B}$ division categories of the autonomous community of Madrid, Spain. A stratified cluster sampling method was used, considering stratification of the categories of the first division, second division $\mathrm{A}$ and second division $\mathrm{B}$.

*Corresponding author: Juan Pablo Hervás-Pérez, Department of Physiotherapy, Health Faculty, Camilo José Cela University, Madrid, Spain; Tel: 34918153131; E-mail: jphervas@ucjc.edu

Received: November 06, 2017; Accepted: December 26, 2017; Published: December 29, 2017

Citation: García-Fernández P, Guodemar-Pérez J, Ruiz-López M, RodríguezLópez ES, Hervás-Pérez JP (2017) Injury Rate in Professional Soccer Players within the Community of Madrid: A Comparative, Epidemiological Cohort Study among the First, Second and Second B Divisions Physiother Rehabil 2: 152. doi: 10.4172/2573-0312.1000152

Copyright: ( 2017 Garcia-Fernández P, et al. This is an open-access article distributed under the terms of the Creative Commons Attribution License, which permits unrestricted use, distribution, and reproduction in any medium, provided the original author and source are credited. 


\section{Participants}

The inclusion criteria consisted of all male players with an existing contract within the first team. Players with old injuries were not excluded and neither were those who were injured when data collection began. In these cases the player was included in the study, however the injury the player was recovering from was not included in the study for statistical analysis and the exposure factor was not registered until the player was completely recovered from said injury. Injuries were defined as an event occurring during a training session or programmed match leading to the absence of the player at the subsequent training session or match [12]. Furthermore we only registered injuries occurring during training sessions or during matches whether these were official or not. Thus, injuries occurring when performing other activities were not recorded. Players who, at the end of the season presented some kind of injury were followed up until final recovery. In the cases in which an injured player abandoned the club during the season, the player was followed up until recovery.

\section{Data collection}

We elaborated a form for data collection based on a UEFA proposal, which was used during the first week of the preseason. In this form we collected personal data, anthropometric data, sports characteristics of each player (position on the field, dominant leg...), date of injury, mechanisms of injury, body area injured, injured structure, diagnosis, severity, minute of match or training results (in the case that this occurred during competition) and time-off (days) for each player together with the sports medical history of the players. Severity of injury was determined by the number of days between the occurrence of injury until medical leave ranging from mild (between 1 and 7 days), moderate (between 8 and 28 days) and severe (more than 28 days).

\section{Procedure}

First, we randomly selected one club of the three first category clubs, one club from the three second-category clubs and two from the six B category clubs. We then informed the selected clubs regarding the study procedure and aim based on an information sheet which also contained instruction and definition of terms for the registry of injuries. All four clubs participated voluntarily and all players signed an informed consent form prior to participation in this study. All injuries occurring throughout the 2016-2017 season between $1^{\text {st }}$ July 2016 and $1^{\text {st }}$ May 2017 were recorded by doctors from the clubs. This included both the pre-season and season periods. All training sessions and matches were performed on natural grass. The number of players in the sample included 100 professional soccer players with an existing contract during the aforementioned season. This sample size was determined considering that each team has 25 federated players.

All players and their legal tutors were informed of the nature and characteristics of the study and signed informed consent prior to participation, in accordance with the principles of the Declaration of Helsinki. The rights of subjects were protected as all clubs were provided with a confidentiality form based on the organic law for protection of personal data.

\section{Data analysis}

A descriptive statistical analysis of the quantitative data was conducted in order to describe the sample. This included the calculation of the mean, standard deviation, maximum, minimum, median figures. The Kolmogorv-Smirnov test was used to determine the normal distribution of the sample. We then drew up contingency tables for the relation between qualitative variables (Crosstabs procedure). The Fisher exact test or Chi squared test was used to compare the independence or influence between two qualitative variables; injured tissue and player position. In addition, ANOVA variance analyses were performed to compare multiple means regarding two conditions. The SPSS 19.0 software package for windows was used for statistical calculations, considering $\mathrm{p}<0.05$.

\section{Results}

In total, 100 professional players were recruited for this study and followed up. All players accepted to participate in this study. No players changed team during the season. The mean age of players was $25.26 \pm$ 4.94 years, error 0.96 , IC: $24.29 ; 26.23$, without differences statistically significant among the categories $(\mathrm{p}=0,121)$, their mean weight was 75.24 \pm 4.51 , error 0.88 , IC: $178.34 ; 180.1$, without differences statistically significant $(\mathrm{p}=0,626)$, and their height was $179.22 \pm 4.48$, error 0.88 , IC: 74.36; 76.12. With differences statistically significant in the size among the categories $(\mathrm{p}=0.000)$ being the $1^{\text {st }}$ Division players those who average more height, $182,36 \mathrm{~cm}(5,98 \mathrm{ft})$ and the $2^{\text {nd }} B$ Division players the shortest with an average $178,04 \mathrm{~cm}(5,84 \mathrm{ft})$. Twenty-five players belonged to the first division, 25 belonged to the second division, and 50 players belonged to the second $\mathrm{B}$ category. Table 1 displays the player position of the study participants. Four players were followed up due to injuries at the end of the season. The follow-up periods for these players were $8,16,21$ and 63 days, respectively.

\section{Injuries incidence and severity}

In total, 142 injuries were recorded, 33 among the first division players, 27 among second division, and 82 among second B division players (46 in one club and 36 in another), these represented $23.2 \%$, $19 \%$ and $57.5 \%$ of all injuries, respectively. Significant $95 \%(p=0.037)$ differences were found between the number of injuries in each category: the injuries were similar between the $1^{\text {st }}$ and $2^{\text {nd }}$ division; however the players of the $2^{\text {nd }}$ division $B$ suffered 0.56 injuries more than those of the $2^{\text {nd }}$ division.

Regarding the total incidence of injuries in our study, we obtained a value of 2.58 injuries for every 1,000 hours exposure. The injury rate during training sessions equaled 1.56 injuries for every 1.000 hours training. During matches, the injury rate registered was 6.6 injuries per 1.000 hours exposure to the risk. Most injuries took place during matches $(51 \%) v s$. training (49\%). During competitive matches more injuries took place in the second part of the match: 89 injuries of the 142 total injuries. When studying these injuries occurring during matches, we found differences among divisions, 5.0 injuries per 1,000 hours in competition in the $2^{\text {nd }}$ division, 5.42 injuries in the $1^{\text {st }}$ division per 1,000 hours of match, and 7.8 injuries in the $2^{\text {nd }}$ division $B$ for every 1,000 hours exposure.

Regarding the injury rate among categories, differences were observed in the total rate of injuries. Thus, the lowest injury rate was registered in the $2^{\text {nd }}$ division: 1.92 injuries/1,000 hours. In the $1^{\text {st }}$ division this was slightly higher: 2.27 injuries/1,000 hours, whereas

\begin{tabular}{|c|c|}
\hline Position & N \\
\hline Defense & 36 \\
\hline Striker & 20 \\
\hline Midfielder & 32 \\
\hline Goalkeeper & 12 \\
\hline Total & 100 \\
\hline
\end{tabular}

Table 1: Distribution of players by position. 
Citation: García-Fernández P, Guodemar-Pérez J, Ruiz-López M, Rodríguez-López ES, Hervás-Pérez JP (2017) Injury Rate in Professional Soccer Players within the Community of Madrid: A Comparative, Epidemiological Cohort Study among the First, Second and Second B Divisions Physiother Rehabil 2: 152. doi: 10.4172/2573-0312.1000152

Page 3 of 7

the highest was the $2^{\text {nd }}$ division $B$ in which the injury rate was 3.03 injuries $/ 1,000$ hours exposure. Finding differences statistically among categories $(\mathrm{p}=0.034)$. In our study each player suffered an average of 1.4 injuries by the end of the season. Most injuries were mild (42.95\%), followed by moderate $(39.43 \%)$ and severe injuries which were the least frequent injury type (17.60\%) (Table 2$)$.

\section{Time-loss}

The time loss of injuries (Figure 1) equaled 756 days for first category players, 796 for second division players, 609 for one of the $2^{\text {nd }}$ division $\mathrm{B}$ teams, and 666 for the remaining $2^{\text {nd }}$ division $\mathrm{B}$ team.

\begin{tabular}{|c|c|c|}
\hline Injury details & Total $(n=142)$ & $95 \% \mathrm{Cl}$ \\
\hline Lower limb injuries & 115 & $80.99 \%$ \\
\hline Hip & 6 & $4.23 \%$ \\
\hline Thigh & 47 & $33.10 \%$ \\
\hline Gluteus & 5 & $3.52 \%$ \\
\hline Knee & 22 & $15.49 \%$ \\
\hline Lower leg & 13 & $9.15 \%$ \\
\hline Ankle & 21 & $14.79 \%$ \\
\hline Foot & 1 & $0.70 \%$ \\
\hline Upper limb injuries & 14 & $9.86 \%$ \\
\hline Trunk injuries & 6 & $4.23 \%$ \\
\hline Head injuries & 7 & $4.93 \%$ \\
\hline \multicolumn{3}{|c|}{ Mechanism of injury } \\
\hline Contact injury & 47 & $33.10 \%$ \\
\hline Non-contact injury & 95 & $66.90 \%$ \\
\hline \multicolumn{3}{|c|}{ Recurrent/new injury } \\
\hline New injury & 127 & $89.44 \%$ \\
\hline Recurrent injury & 15 & $10.56 \%$ \\
\hline \multicolumn{3}{|c|}{ Injury severity } \\
\hline Mild & 61 & $42.96 \%$ \\
\hline Moderate & 56 & $39.44 \%$ \\
\hline Severe & 25 & $17.60 \%$ \\
\hline
\end{tabular}

Table 2: Injury details

\section{Mechanism and nature of injuries}

The mechanism of injury was mainly due to physical contact $(66.9 \%$ vs. $33.1 \%$ non-contact injuries) not finding differences statistically among categories $(\mathrm{p}=0.710)$ (Table 2$)$. Up to $10.56 \%$ of injuries were recurrent. Two peaks in the incidence of injuries were observed: in January and in the last two months of competition, independent of the category.

\section{Location (body part)}

If we analyze the injuries per body region, in our study we observed that most injuries affected the lower limb (Table 2), in which 115 injuries were registered, equaling a percentage of $80.98 \%$ over the total injuries. In this region, the most affected area was the thigh, presenting the greatest number of injuries (Table 2). In second place, although at a lower rate, we encountered upper limb injuries, 14 injuries in total, representing $9.58 \%$ of injuries. Head injuries $4.92 \%$ of which there were 2 cases and lastly in the trunk, 6 injuries were reported representing $4.92 \%$ of the total.

\section{Location (tissue)}

Muscle injuries were most frequent in our study, in total 74 muscle injuries were recorded, representing $52.10 \%$ of the total injuries. Thus, muscle injuries represented more than half of the total injuries recorded. Joint injuries were the second most frequent tissue affected, with 49 injuries recorded in this sample, representing $34.50 \%$ of the total injuries. Significantly lower figures corresponded to bone injuries and contusions, of which we registered 9 and 10 cases respectively. The hamstrings were the muscles that suffered the most injuries in our study we registered 31 injuries in this area, which in percentage represented $42.46 \%$ of the total muscle injuries registered. In second place regarding the number of muscle injuries we found the triceps surae muscle, in which 13 injuries were registered, representing $17.80 \%$ of the total and in fourth place, 10 injuries affecting the quadriceps muscle were

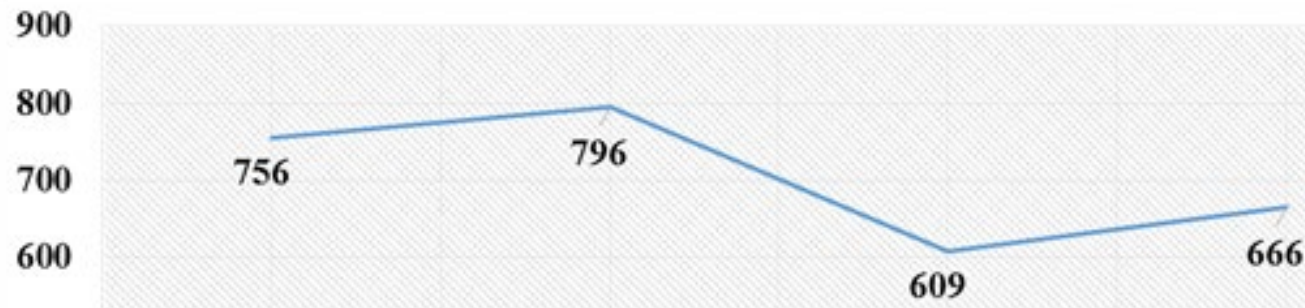

500

400

300

200

100

0
1st Division
2nd Division
2nd Division B
2nd Division B

Figure 1: Time loss (in days). 
Citation: García-Fernández P, Guodemar-Pérez J, Ruiz-López M, Rodríguez-López ES, Hervás-Pérez JP (2017) Injury Rate in Professional Soccer Players within the Community of Madrid: A Comparative, Epidemiological Cohort Study among the First, Second and Second B Divisions Physiother Rehabil 2: 152. doi: 10.4172/2573-0312.1000152

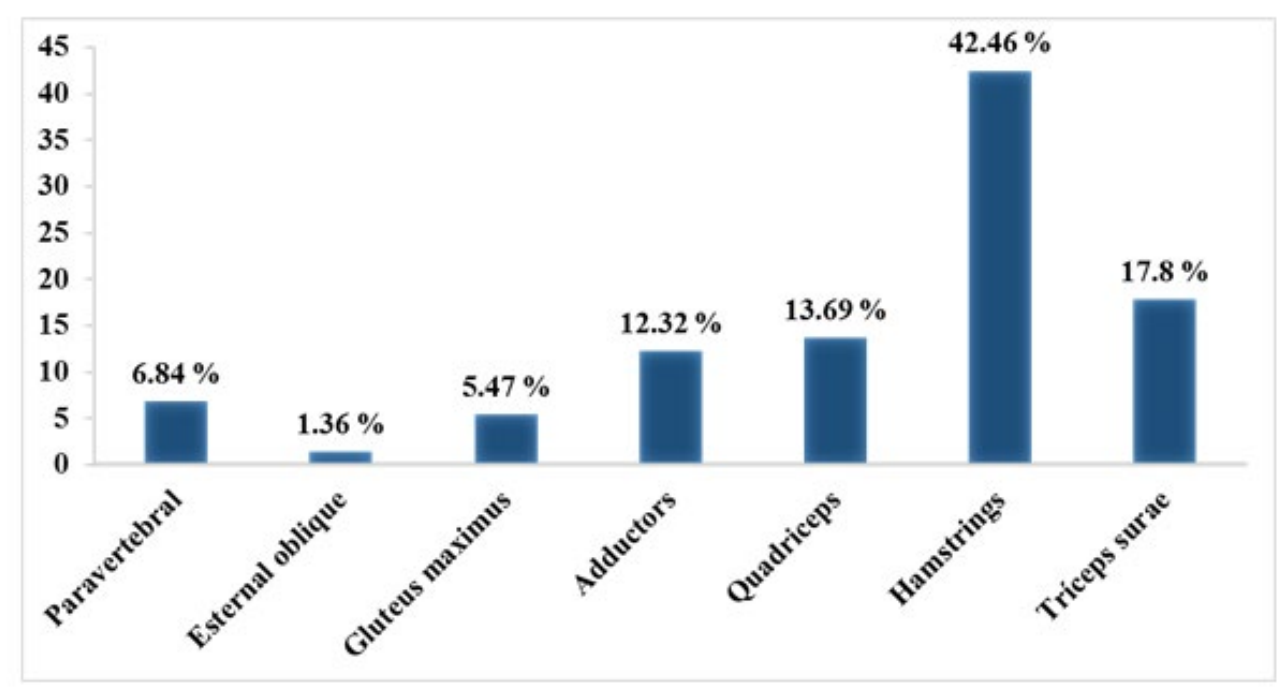

Figure 2: Percentage of Injuries per muscle.

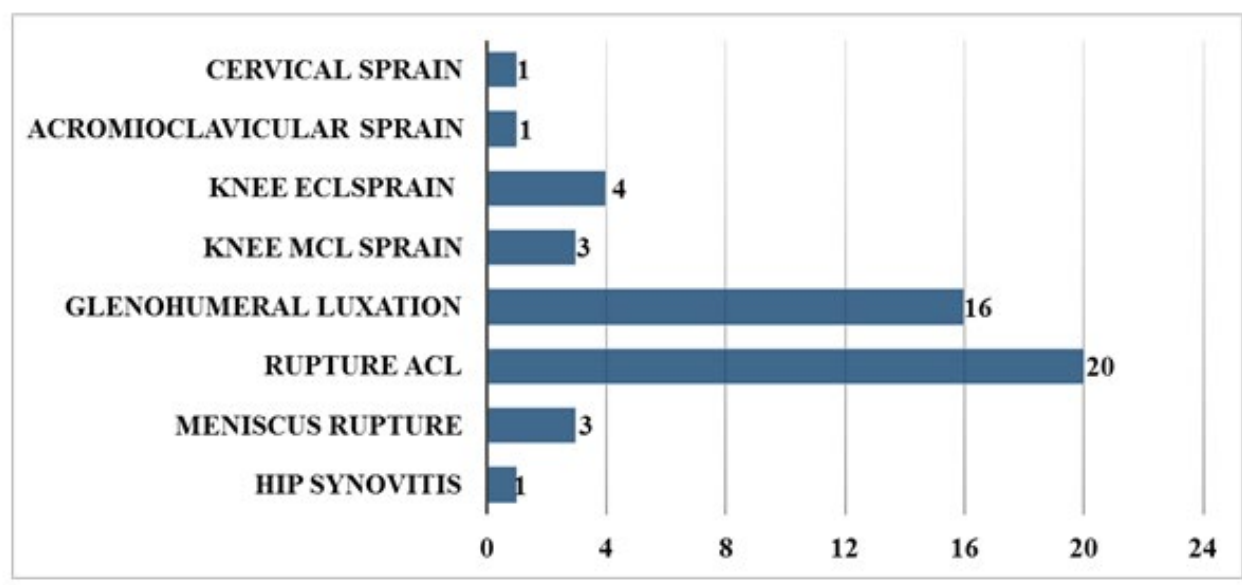

Figure 3: Number of injuries per joint.

\begin{tabular}{|c|c|c|}
\hline Categories, Position and Age & Total $(\mathbf{n = 1 4 2 )}$ & $\mathbf{9 5 \%} \mathbf{C l}$ \\
\hline First division & 33 & $23.20 \%$ \\
\hline Second division & 27 & $19.00 \%$ \\
\hline Second division B & 82 & $57.70 \%$ \\
\hline Defense players & 59 & $41.50 \%$ \\
\hline Striker & 39 & $27.50 \%$ \\
\hline Midfielder & 37 & $26.10 \%$ \\
\hline Goalkeeper & 7 & $4.90 \%$ \\
\hline$<20$ & 31 & $21.83 \%$ \\
\hline $21-25$ & 43 & $30.28 \%$ \\
\hline $26-30$ & 39 & $27.46 \%$ \\
\hline$>30$ & 29 & $20.42 \%$ \\
\hline
\end{tabular}

Table 3: Injury by player category, position and age.

reported, representing $13.69 \%$ of all injuries (Figure 2).

In our study, joint injuries were the second most frequent injuries after muscle injuries. We registered 49 joint injuries, representing $34.50 \%$ of the total. Within the joint injuries, ankle sprains affecting the lateral collateral ligament were the most frequent, with a total of 20 injuries, which represented $40.81 \%$ of the total. In second place the medial collateral knee ligament, of which we had 16 cases, representing $32.65 \%$ of all injuries (Figure 3 ).

\section{Injuries by player position and age}

We found statistically significant differences 95\% $(p=0.000)$ between the number of injuries and the positions held by players on the field. The strikers are the players who in proportion suffer the most injuries, suffering 0.79 more injuries than midfielders and 1.37 more injuries than goalkeepers. In second place, the defenders suffered 1.06 injuries more than goalkeepers. The analysis of injuries by age revealed that the age group suffering the greatest amount of injuries was from 21 to 25 years, suffering 43 injuries, representing $30.28 \%$ of the total 
injuries. The players with the least injuries were those belonging to the group of over 30 years old, who suffered 29 injuries, representing a total percentage of $20.42 \%$ (Table 3 ).

\section{Discussion}

This study sought to provide a comprehensive analysis and description of the injuries sustained by professional elite soccer players in the community of Madrid among three different divisions. We were unable to find studies in the literature that compared the injuries within the different soccer categories. However, we have found studies that report a similar number of injuries compared to ours. Thus, Crozier et al. [11] performed a study based on a team of the British Premier league, reporting that 39.1 injuries occurred during one season. We found significant differences in the number of injuries sustained by players in different categories, with players in the second B division sustaining more injuries. We believe this is due to several factors. On the one hand, the fact that the players in the second division $B$ are frequently semiprofessionals and perform other professional work besides their sports occupation and the fact that training and competing after 8 hours' work can be a factor that predisposes players to have an injury. On the other hand, on a technical level, regarding coaches and trainers, their technical level is inversely proportional to the team's category and therefore, it can be assumed that there is a great variability in the training systems and a worse control of the overload player's experience, which is also conditioned by past experiences. All of these may be a risk factor in the appearance of injuries. Thus, we believe that the category is a factor that affects the number of injuries suffered by the soccer player, as the number of injuries is inversely proportional to the player's category.

Strikers suffered the most injuries, independent of their playing category. Naturally, these differences may be due to the peculiarities of each position in the game, with strikers suffering many more tackles on behalf of the defenders, performing explosive sprints, and their actions are on occasion extreme, due to the possibility of scoring a goal. In contrast, the goalkeepers suffer less injury as they do not suffer tackles on a regular basis by other players, they cannot be touched in the small area and they do not perform sprints on a regular basis. Thus, we can affirm that the position occupied by the player on the field is a factor that influences the number of injuries suffered by soccer players.

When comparing our data with those obtained in other studies, we observe a considerable disparity regarding injury rates. Steffen et al. [13] performed a comparative study regarding the injury risk in different playing surfaces reporting a total average of injuries per 1,000 hours' exposure equaling 2.8 which corresponds to an injury risk of 1.2 injuries per 1,000 hours training, while during matches the injury rate was 8.7 injuries per 1,000 playing hours [13]. Furthermore, we detected a clear tendency in the fact that, the older the studies are the greater the injury risk seems to be however the more recent studies report data that is more similar to our study. This may be due to decreased permissiveness regarding rough play and a stricter application of the playing rules based on the recommendations made in 2004 by the International Soccer Association Board [14]. Regarding injury rates by division, Noya and Sillero, in their study performed in the $1^{\text {st }}$ and $2^{\text {nd }}$ division of the Spanish league, reported an injury rate in the $2^{\text {nd }}$ division of 8.9 injuries/1,000 hours' exposure and in the $1^{\text {st }}$ division this figure was 9.0 injuries/1,000 hours' exposure to the risk [4].

The significant differences found between categories are due to the injury rate during competition. This confirms prior studies which have reported a greater incidence of injury during competition. Noya and
Sillero [15] report an injury rate during training in the $1^{\text {st }}$ division of 6.2 injuries per 1,000 hours training and 6.3 injuries per 1,000 hours' exposure.

In our study each player suffered an average of 1.4 injuries by the end of the season. Similar findings were reported by Crozier and Taylor, Hawkins et al. [11,16] who reported 1.3 and 1.4 injuries per player and per season.

Our finding regarding the lower limb as the most injured body part is in consensus with the literature [6,11,13,15,17-34]. Muscle injuries were most frequent in our study, representing over half of the total injuries recorded. The literature reviewed confirmed the higher incidence of muscle injuries, as the most frequent injuries in soccer $[5,10,16,22,23,25,27,35-41]$.

The hamstrings muscles were the site of the most muscle injuries, representing $42.46 \%$ of the total muscle injuries registered. We found several studies which support these findings [4,20,42-45]. We believe that this finding may be explained by extrinsic factors, such as the characteristics of the playing terrain, as soccer is practiced on changing surfaces due to the climate, the length of the grass, the amount of watering prior to the match, etc., and the length and shape of the studs or intrinsic factors such as a muscle imbalance with the knee extensor muscles. Thus, we can affirm that the most affected muscles in soccer are the hamstring muscles.

In our study, joint injuries were the second most frequent injuries after muscle injuries, representing $34.50 \%$ of the total. Within the joint injuries, the ankle sprains affecting the lateral collateral ligament were the most frequent. In the literature reviewed we have found a number of studies that identify joint injuries as the second most frequent after muscle injuries $[4,5,16,22,27,46,34-47]$. Thus, we can affirm that joint injuries are the second most frequent after muscle injuries.

The analysis of injuries by age revealed that the age group suffering the greatest amount of injuries was from 21 to 25 years, suffering 43 injuries, representing $30.28 \%$ of the total injuries. The players with the least injuries were those belonging to the group of over 30 years old, who suffered 29 injuries, representing a total percentage of $20.42 \%$. We were unable to find published reports to compare the tendency regarding injuries by age. However, we have found studies stating that the number of injuries sustained by players increases with age [47]. However, this contrasts with other reports, as according to Carr most injuries occur in teenage years.

More injuries took place in the second part of matches, confirming findings by prior studies $[10,11,16,23,27,36,41]$ and may be due to the physical and psychical tiredness that the soccer player accumulates during the match, which makes the player more vulnerable to suffer injuries.

We also observed that the players in our study sustained more injuries when they were losing $(51.40 \%)$, than when they were equal (26.76\%) or were winning (21.83\%) [20] reported similar data, a greater injury rate when the score was equal or winning, which could be due to the stress and anxiety associated with an adverse score. Further studies are required with larger samples to confirm these results and over longer time periods [48].

\section{Conclusion}

This report provides details regarding the characteristics and incidence of injuries in professional soccer players in Spain. These findings offer insight to the prevalence of injuries in this population and 
Citation: García-Fernández P, Guodemar-Pérez J, Ruiz-López M, Rodríguez-López ES, Hervás-Pérez JP (2017) Injury Rate in Professional Soccer Players within the Community of Madrid: A Comparative, Epidemiological Cohort Study among the First, Second and Second B Divisions Physiother Rehabil 2: 152. doi: 10.4172/2573-0312.1000152

may help improve injury prevention programs, especially regarding the lower categories.

\section{Key Points}

\section{Findings}

1. The injury rate in professional soccer players in the Community of Madrid, Spain is 2.58 injuries per 1000 hours exposure. This injury rate decreases in higher categories: with a 2.27 injury rate in the first division, 1.92 in the second division and 3.03 in the second division $\mathrm{B}$.

2. The most frequent injuries in soccer are mild (42.95\%), followed by moderate $(39.43 \%)$ and severe $(17.60 \%)$ injuries.

\section{Implications}

Soccer clubs and medical teams working with professional soccer players should consider these findings in order to improve current injury prevention strategies, especially regarding players in the lower categories.

\section{Caution}

Minor injuries not requiring time off from play were not included in the definition of injury. External validity is limited due to the reduced sample size.

\section{References}

1. CSD (2009) Manual of the Census agent, Census. Madrid: Ministry of education and science. superior council of sports.

2. Warden F, Soccer (2009) Phenomenon of phenomena. Madrid: LID.

3. Ekstrand J, Walden M, Hagglund M (2004) A congested soccer calendar and the wellbeing of players: Correlation between match exposure of European footballers before the World Cup 2002 and their injuries and performances during that World Cup. Br J Sports Med 38: 493-497.

4. Noya J, Sillero M (2012) Incidence of injury in Spanish professional football over a season: days of injury leave. Apunts Med Esport 47: 115-123.

5. Walden M, Hagglund M, Ekstrand J (2005) UEFA Champions League study: A prospective study of injuries in professional soccer during the 2001-2002 season. Br J Sports Med 39: 542-546.

6. Tscholl P, O'Riordan D, Fuller CW, Dvorak J, Gutzwiller F, et al. (2007) Causation of injuries in female soccer players in top-level tournaments. $\mathrm{Br} J$ Sports Med 41: 8-14.

7. Gibbs N (1993) Injuries in professional rugby league. A three-year prospective study of the South Sydney professional rugby league soccer club. Am J Sports Med 21: 696-700.

8. Gissane C, Jennings D, Kerr K, White JA (2002) A pooled data analysis of injury incidence in rugby league soccer. Sports Med 32: 211-216.

9. Woods C, Hawkins RD, Maltby S, Hulse M, Thomas A, et al. (2004) The footbal association medical research programme: An audit of injuries in professional football-analysis of hamstring injuries. $\mathrm{Br} \mathrm{J}$ Sports Med 38: 36-41.

10. Arnason A, Gudmundsson A, Dahl HA, Johannsson E (1996) Soccer injuries in Iceland. Scand J Med Sci Sports 6: 40-45.

11. Crozier A, Taylor G (2001) An audit of injuries in professional soccer. The soccer association.

12. Hagglund M, Walden M, Bahr R, Ekstrand J (2005) Methods for epidemiological study of injuries to professional football players: Developing the UEFA model. Br J Sports Med, 39: 340-346.

13. Steffen $K$, Andersen TE, Bahr R (2007) Risk of injury on artificial turf and natural grass in young female football players. Br J Sports Med 41: 33-37.

14. Fuller CW, Smith GL, Junge A, Dvorak J (2004) The influence of tackle parameters on the propensity for injury in international football. Am J Sports Med 32: 43-53.
15. Javier NS, Sillero Manuel SQ (2013) Epidemiology of injuries in Spanish professional football in the 2008-2009 season. Sport Med Arch 30: 750-766.

16. Hawkins RD, Hulse MA, Wilkinson C, Hodson A, Gibson M (2001) The association football medical research programme: An audit of injuries in professional football. Br J Sports Med 35: 43-47.

17. Adamczyk G, Luboiñski, L (2002) Epidemiology of football related injuries part I. Jesien 3: 236-260.

18. Andersen TE, Engebretsen L, Bahr R (2004) Rule violations as a cause of injuries in male Norwegian professional football: Are the referees doing their job? Am J Sports Med 32: 62S-68S.

19. Dick R, Putukian M, Agel J, Evans TA, Marshall SW (2007) Descriptive epidemiology of collegiate women's soccer injuries. National Collegiate Athletic Association injury Surveillance System, 1988-1989 Through 2002-2003. J Ath Train 42: 278-285.

20. Ekstrand J, Hagglund M, Walden M (2011) Epidemiology of muscle injuries in professional football (soccer). Am J Sports Med 39: 1226-1232.

21. Hägglund M (2007) Epidemiology and prevention of football injuries. U-Trick. Linköping, Sweden.

22. Hagglund M, Walden M, Ekstrand J (2005) Injury incidence and distribution in elite football-a prospective study of the Danish and the Swedish top divisions. Scand J Med Sci Sports 15: 21-28.

23. Hawkins RD, Fuller CW (1999) A prospective epidemiological study of injuries in four English professional football clubs. Br J Sports Med 33: 196-203.

24. Jacobs SJ, Berson BL (1986) Injuries to runners: A study of entrants to a 10,000 meter race. Am J Sports Med 14: 151-155.

25. Junge A, Dvorak J, Graf-Baumann T (2004) Football injuries during the World Cup 2002. Am J Sports Med 32: 23-27.

26. Lilley K, Gass E, Locke S. A retrospective injury analysis of state representative female soccer players. Physic Ther Spor 3: 2-9.

27. Luthje P, Nurmi I, Kataja M, Belt E, Helenius P, et al. Epidemiology and traumatology of injuries in elite soccer: a prospective study in Finland. Scand $J$ Med Sci Sports 6: 180-185.

28. McGrath A, Ozanne-Smith J (1997) Heading injuries out of soccer: A review of the literature: Monash University Accident Researcg Centre, 125.

29. Morgan BE, Oberlander MA (2001) An examination of injuries in major league soccer. The inaugural season. Am J Sports Med 29: 426-430.

30. Paus V, Torrengo F (2006) Incidence of Injuries in professional soccer players J Argentine Associ Sports Traumatol 10: 10-17.

31. Stumbo MD (2005) Incidence of sports injuries in Argentine women's socce teams of the A.F.A. J Argenti Associat Sports Traumatol 1.

32. Tegnander A, Olsen OE, Moholdt TT, Engebretsen L, Bahr R (2008) Injuries in Norwegian female elite soccer: a prospective one-season cohort study. Knee Surg Sports Traumatol Arthrosc 16: 194-198.

33. Walden M, Hagglund M, Ekstrand J (2005) Injuries in Swedish elite football-a prospective study on injury definitions, risk for injury and injury pattern during 2001. Scand J Med Sci Sports 15: 118-125.

34. Woods C, Hawkins R, Hulse M, Hodson A (2002) The football association medical research programme: an audit of injuries in professional socceranalysis of preseason injuries. $\mathrm{Br} \mathrm{J}$ Sports Med 36: 436-441.

35. Dadebo B, White J, George K (2004) A survey of flexibility training protocols and hamstring strains in professional football clubs in England. $\mathrm{Br} \mathrm{J}$ Sports Med 38: 388-394.

36. Engström B, Forssblad M, Johannsson C, Törnkvist H (1990) Does a major knee injury definitely sideline an elite soccer player? Am J Sports Med 18 101-105.

37. Peterson L, Junge A, Chomiak J, Graf-Baumann T, Dvorak J (2000) Incidence of football injuries and complaints in different age groups and skill-level groups. Am J Sports Med 28: 51-57.

38. Price RJ, Hawkins RD, Hulse MA, Hodson A (2004) The football association medical research programme: an audit of injuries in academy youth soccer. $\mathrm{Br}$ J Sports Med 38: 466-471.

39. Villani A, Mártinez D, Lamas R, Fernández J (2003) Statistical analysis of 
Citation: García-Fernández P, Guodemar-Pérez J, Ruiz-López M, Rodríguez-López ES, Hervás-Pérez JP (2017) Injury Rate in Professional Soccer Players within the Community of Madrid: A Comparative, Epidemiological Cohort Study among the First, Second and Second B Divisions Physiother Rehabil 2: 152. doi: 10.4172/2573-0312.1000152

sports injuries in soccer players that made up youth selections of the AFA. $\mathrm{J}$ Argent Associat Sports Traumatol 1: 18-27.

40. Volpi P, Melegati G, Tornese D, Bandi M (2004) Muscle strains in soccer: A five-year survey of an Italian major league team. Knee Surg Sports Traumato Arthrosc 12: 482-485.

41. Woods C, Hawkins R, Hulse M, Hodson A (2003) The football association medical research programme: An audit of injuries in professional soccer: an analysis of ankle sprains. Br J Sports Med 37: 233-238.

42. Dauty M, Collon S (2011) Incidence of injuries in French professional soccer players. Int J Sports Med 32: 965-969.

43. Freckleton G, Pizzari T (2013) Risk factors for hamstring muscle strain injury in sport: a systematic review and meta-analysis. Br J Sports Med 47: 351-358.
44. Mallo J, Dellal A (2012) Injury risk in professional football players with special reference to the playing position and training periodization. J Sports Med Phys Fitness 52: 631-638.

45. van Beijsterveldt AMC, van de Port IGL, Vereijken AJ, Backx FJG (2012) Risk factors for hamstring injuries in male soccer players: A systematic review of prospective studies. Scand J Med Sci Sports 23: 253-262.

46. Mallo J (2012) Lesion incidence in footballers: 2nd Division B. J phy prepara soccer 3: 84-95.

47. Bahr R, Reeser JC (2003) Injuries among world-class professional beach volleyball players. The Federation Internationale de volleyball beach volleyball injury study. Am J Sports Med 31: 119-125.

48. Carr KE (2003) Musculoskeletal injuries in young athletes. Clin Fam Pract 5 $385-415$. 